\title{
Exigências Nutricionais de Lisina para Codornas durante a Fase de Postura, em Função do Nível de Proteína da Ração ${ }^{1}$
}

\section{Marcelo Luís Gomes Ribeiro ${ }^{2,3}$, José Humberto Vilar da Silva ${ }^{3}$, Manuel de Oliveira Dantas ${ }^{4}$, Fernando Guilherme Perazzo Costa ${ }^{4}$, Sérgio Felix de Oliveira ${ }^{5}$, José Jordão Filho ${ }^{5}$, Edson Lindolfo da Silva ${ }^{5}$}

\begin{abstract}
RESUMO - O experimento objetivou estimar as exigências de lisina total e a relação lisina: proteína em codornas, na fase de produção. Foram utilizadas 320 codornas, resultado do cruzamento entre a codorna japonesa e a européia de 60 a 144 dias de idade, com peso vivo médio de 178+12 g, alimentadas com rações contendo 20 e $23 \%$ de proteína bruta (PB) e, 0,80; 0,95; 1,10;1,25 e 1,40\% de lisina. O delineamento experimental foi o inteiramente ao acaso em esquema fatorial 2x5 (dois níveis de PB x cinco níveis de lisina), que resultou em dez tratamentos, cada um com quatro repetições de oito aves. As codornas foram submetidas a um programa de luz de 17 horas de duração e alimentadas à vontade. As variáveis estudadas foram obtidas em quatro períodos de 21 dias. Houve efeito quadrático dos níveis de lisina sobre a produção de ovos, sendo a exigência e o consumo, respectivamente, de $1,07 \%$ e $287 \mathrm{mg}$ de lisina/dia com $20 \% \mathrm{~PB}$ e de $1,15 \%$ e $321 \mathrm{mg}$ de lisina/dia com 23\%PB. O nível de 23\%PB aumentou o consumo de ração, produção, peso e massa de ovos e também melhorou a conversão alimentar por massa e dúzia de ovos. As relações lisina: PB não foram alteradas, sendo de 5,3 e 5,0\%, respectivamente, com 20 e $23 \%$ de PB na ração. Os resultados do presente estudo sugerem aumento quantitativo da exigência de lisina de codornas na fase de produção, mas não da relação lisina: PB, à medida que a concentração de PB na ração é elevada.
\end{abstract}

Palavras-chave: peso do albumem e gema, produção de ovos, qualidade da casca do ovo

\section{Nutritional Requirement of Lysine for Laying Quails in Function of the Level of Diets Crude Protein}

ABSTRACT - This experiment was carried out to estimate the requirements of total lysine and lysine: crude protein (CP) ratio to laying quails. It was used three hundred and twenty birds offspring from crossing breeding of Japanese and European quails from 60 to 144 days of age, live weight of $178+12 \mathrm{~g}$, fed diet with 20 and $23 \%$ of CP, and five rates of lysine $(0.80,0.95,1.10,1.25$ and $1.40 \%)$. A completely randomized experimental design in a factorial scheme $2 \times 5$ (two CP levels X five rates of lysine) was used, resulting in ten treatments, each one with four replications of eight layers quail submitted to a light schedules of 17 hours daily and ad libitum fed. The studied variables were obtained in four periods of 21 days. There was effect of lysine rates within CP levels on egg production, with requirements of $1.07 \%$ lysine with $20 \% \mathrm{CP}$ and $1.15 \%$ with $23 \% \mathrm{CP}$. The $23 \% \mathrm{CP}$ level increased feed intake, egg production, egg weight and egg mass, and also improved feed to egg mass ratio and feed to egg dozen ratio. The lysine: CP ratio did not was affect (5.3 versus $5.0 \%$ ) when crude protein diets increase 20 to $23 \%$. Results in the present study suggest increase of quantitatively requirement of lysine of quail layer, but not lysine: CP ratio, when increase CP concentration on diet.

Key Words: albumen and yolk weight, egg shell quality, egg production

\section{Introdução}

$\mathrm{Na}$ alimentação de codornas, a ração representa cerca de 65 a $70 \%$ do custo de produção, sendo a proteína (aminoácidos) responsável por cerca de $25 \%$ deste custo, que em casos de erros nas dosagens de nutrientes, especialmente os aminoácidos, pode ser ainda maior, podendo causar danos ao desempenho das aves pelo imbalanço, antagonismo e toxidez
(Silva \& Ribeiro, 2001).

O aminoácido lisina é considerado padrão no conceito de proteína ideal, balanceamento teoricamente ideal de proteína, e vem sendo usado como referência para atualizar as necessidades de outros aminoácidos, por intermédio de relações simples (Silva \& Ribeiro, 2001). A lisina também tem papel importante no organismo, na síntese de carnitina, que atua no transporte de ácidos graxos para a beta-oxidação

\footnotetext{
1 Parte da Dissertação de Mestrado do primeiro autor

2 Aluno do Mestrado em Zootecnia - DZ-CCA-UFPB-Campus III Areia-PB. Bolsista do PICDT/Capes.

${ }^{3}$ Professor DAP/CFT/UFPB/Bananeiras/PB/Brasil.CEP58.220.000. E.mail: marcelo@cft.ufpb.br; jvilar@cft.ufpb.br

${ }^{4}$ Professor do DZ-CCA-UFPB-Campus III. Areia-PB. E.mail: fperazzo@cca.ufpb.br

${ }^{5}$ Aluno do curso de Graduação em Licenciatura em Ciências Agrárias - Bananeiras-UFPB.
} 
na mitocôndria, na formação da matriz óssea em animais jovens e no crescimento muscular.

As recomendações de proteína para codornas em produção variam de $20 \%$ (Lesson \& Summers, 1997; NRC, 1994) a 21\% (Fabichak, 1987) e 22,4\% (Pinto et al., 1998), e estes valores estão além dos normalmente recomendados para galinhas poedeiras de 1617\% (Rostagno et al., 2000). As recomendações de lisina, por sua vez, variam de $0,8 \%$ (Lesson \& Summers, 1997) a 1,0\% (NRC, 1994) em rações contendo $20 \% \mathrm{~PB}$, resultando em diferentes relações lisina: proteína.

Estudos recentes têm mostrado, claramente, que as exigências de metionina (Silva et al., $1998 \mathrm{ab}$ ), triptofano, valina e lisina (Morris et al., 1999), em frangos de corte, crescem linearmente com o aumento do nível de proteína na ração. Entretanto, nenhum estudo ainda foi realizado para testar esta evidência com codornas, como também avaliar se a relação lisina: proteína exigida por esta espécie sofre alteração, à medida que mais proteína é adicionada à ração.

Por outro lado, as formulações de rações para codornas dependem de dados contidos em tabelas estrangeiras, obtidas em condições ambientais muito diferentes da brasileira (Silva \& Ribeiro, 2001). A maioria dos dados compilados pelo NRC (1994) foi obtida há quase vinte anos (Shim \& Vohra, 1984) com aves apresentando potencial genético bastante diferente das codornas criadas atualmente.

Os objetivos deste trabalho foram determinar as exigências em lisina para codornas e avaliar se a relação lisina: proteína bruta é alterada pelo nível de proteína da ração.

\section{Material e Métodos}

O experimento foi conduzido no Setor de Avicultura do Centro de Formação de Tecnólogos, Campus de Bananeiras/UFPB.

Foram utilizadas 320 codornas, resultado do cruzamento entre codornas japonesas (Coturnix coturnix japonica) e codornas européias (Coturnix coturnix coturnix), com peso vivo médio inicial de 178+12 g, na fase de 60 a 144 dias de idade. As aves foram alojadas aos 50 dias em gaiolas sobrepostas, de arame galvanizado com $0,33 \times 0,33 \times 0,16 \mathrm{~m}$, e alimentadas com rações e água à vontade, durante quatro períodos de 21 dias. O programa de luz (luz natural + artificial) adotado teve duração de 17 horas diárias.

Os dados de temperatura e umidade relativa do ar foram registrados três vezes ao dia, utilizando-se um termohigrômetro digital. Durante o experimento, os dados médios obtidos de temperatura e umidade máximas e mínimas foram, respectivamente, de 29,5 e $21,9^{\circ} \mathrm{C}$ e de 90,5 e $49,8 \%$.

Duas rações basais (Tabela 1) foram formuladas para conter 20 e $23 \%$ de PB e atender as necessidades das codornas em postura em todos os nutrientes, exceto lisina, que foi suplementada com $\mathrm{L}$-lisina $\cdot \mathrm{HCl}$ (78,4 \% de lisina), em substituição ao amido de milho, em proporções iguais nas rações, em 0,$00 ; 0,191$; 0,$383 ; 0,574$ e $0,765 \%$, resultando, respectivamente, em 0,$80 ; 0,95 ; 1,10 ; 1,25$ e 1,40\% de lisina nas rações.

As variáveis estudadas foram consumo de ração, produção de ovos, peso e massa de ovos, conversão alimentar por massa e por dúzia de ovos. A produção de ovos (ave/dia) foi acompanhada, diariamente, enquanto o peso foi obtido com a pesagem dos ovos produzidos nos últimos cinco dias de cada período experimental. Os pesos de albúmem, gema e cascas foram obtidos após separação manual destes componentes. A porcentagem de casca seca foi obtida pela quebra e secagem das casca em estufa a $105^{\circ} \mathrm{C}$ por 24 horas.

$\mathrm{O}$ delineamento experimental foi o inteiramente ao acaso em esquema fatorial 2 × 5 (dois níveis de proteína $\mathrm{x}$ cinco níveis de lisina), totalizando dez tratamentos, cada um com quatro repetições de oito aves. Os dados foram analisados de acordo com o seguinte modelo estatístico:

$$
\mathrm{Y}_{\mathrm{ijk}}=\mathrm{m}+\mathrm{L}_{\mathrm{i}}+\mathrm{NP}_{\mathrm{j}}+\mathrm{L}^{*} \mathrm{NP} \mathrm{P}_{(\mathrm{ij})}+\mathrm{e}_{\mathrm{ijk}}
$$

em que $\mathrm{Y}_{\mathrm{ijk}}=$ variável observada na $\mathrm{k}$-ésima repeti-

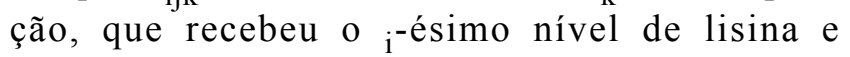
o ${ }_{j}$-ésimo nível de proteína; $m=$ média geral do experimento; $\mathrm{L}_{\mathrm{i}}=$ efeito do ${ }_{\mathrm{i}}$-ésimo nível de lisina da ração, sendo ${ }_{i}=0,80,0,95,1,10,1,25$ e $1,40 \%$ de

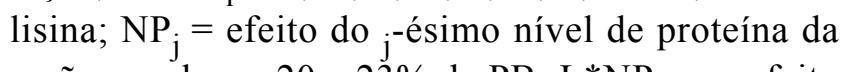
ração, sendo ${ }_{j}=20$ e $23 \%$ de PB; $L^{*} N P{ }_{(i j)}=$ efeito da interação do ${ }_{\mathrm{i}}$-ésimo nível de lisina com o $\mathrm{j}$-ésimo nível de proteína; $\mathrm{e}_{\mathrm{ijk}}=$ erro aleatório, $\operatorname{NID}\left(0, \sigma^{2}\right)$.

As análises estatísticas foram realizadas de acordo com o programa SAEG (Sistema de Análises Estatísticas e Genéticas), desenvolvido pela UNIVERSIDADE FEDERAL DE VIÇOSA - UFV (1983). Quando as interações foram significativas $(\mathrm{P}<0,05)$ realizaram-se os desdobramentos das mesmas com o objetivo de serem realizadas análises de regressão em função dos níveis de lisina, dentro de cada nível de proteína da ração, considerando-se o

R. Bras. Zootec., v.32, n.1, p.156-161, 2003 
Tabela 1 - Composição percentual e química das rações com base na matéria natural ${ }^{1}$

Table 1 - Percentage and chemical compositions of basal diets as $\mathrm{fed}^{1}$

\begin{tabular}{|c|c|c|}
\hline \multirow[t]{2}{*}{$\begin{array}{l}\text { Ingrediente } \\
\text { Ingredient }\end{array}$} & \multicolumn{2}{|c|}{$\begin{array}{c}\text { \%Proteína } \\
\text { Protein level }\end{array}$} \\
\hline & 20 & 23 \\
\hline Milho moído, 9,18\% PB (Ground corn) ${ }^{2}$ & 61,96 & 54,08 \\
\hline Farelo de soja, 45\% PB (Soybean meal) ${ }^{2}$ & 15,35 & 20,13 \\
\hline Glúten de milho, $60 \% \mathrm{~PB}$ (Corn gluten $)^{2}$ & 11,24 & 15,00 \\
\hline Farelo de trigo (Wheat bran) & 2,00 & 1,00 \\
\hline Calcário calcítico (Limestone) & 5,71 & 5,70 \\
\hline Fosfato bicálcico (Dicalcium phosphate) & 1,34 & 1,32 \\
\hline L-lisina $\cdot \mathrm{HCl} 78,4 \%($ L-Lysine $\cdot \mathrm{HCl}-78.4 \%)$ & 0,15 & 0,02 \\
\hline DL-metionina (DL-Methionine 99\%) & 0,10 & 0,04 \\
\hline Óleo vegetal (Vegetable oil) & 0,50 & 1,06 \\
\hline Amido de milho (Corn starch) & 1,00 & 1,00 \\
\hline Premix vitamínico (Vitamin premix) ${ }^{3}$ & 0,10 & 0,10 \\
\hline Premix mineral(Mineral premix) ${ }^{4}$ & 0,05 & 0,05 \\
\hline Cloreto de colina (Choline choride) & 0,20 & 0,20 \\
\hline $\mathrm{BHT}^{5}$ & 0,01 & 0,01 \\
\hline Sal (Salt) & 0,30 & 0,29 \\
\hline Total & 100,00 & 100,00 \\
\hline Matéria seca (\%) (Dry matter) & 85,84 & 86,31 \\
\hline Proteína bruta $(\%)^{6}$ (Crude protein) & 20,00 & 23,00 \\
\hline Energia metabolizável (kcal/kg) & 3000 & 3000 \\
\hline \multicolumn{3}{|l|}{ Metabolizable energy } \\
\hline Cálcio (\%) (Calcium) & 2,55 & 2,55 \\
\hline Fósforo disponível (\%) & 0,35 & 0,35 \\
\hline \multicolumn{3}{|l|}{ Available phosphorus } \\
\hline Lisina $(\%)(\text { Lysine })^{6}$ & 0,80 & 0,80 \\
\hline Metionina + cistina $(\%)$ & 0,76 & 0,77 \\
\hline \multicolumn{3}{|l|}{ Methionine + cystine } \\
\hline Metionina (\%) (Methionine) & 0,46 & 0,46 \\
\hline Sódio (\%) (Sodium) & 0,15 & 0,15 \\
\hline
\end{tabular}

${ }^{1}$ Exigências nutricionais de acordo com o NRC (1994).

${ }^{1}$ Nutritional requirements according to NRC (1994).

2 Valores tabelados (Rostagno et al., 2000).

2 Tabling values (Rostagno et al., 2000).

3 Premix vitamínico (Vitamin premix) - $\mathrm{kg}$ do produto ( $k g$ of product): Vit. A, 40.000.000 UI; Vit. D3, 8.000.000 UI; Vit. E, 100.000 UI; Vit. $\mathrm{K}_{3}, 6.000,0 \mathrm{mg}$; Vit. $\mathrm{B}_{1}, 6.000,0 \mathrm{mg}$; Vit. $\mathrm{B}_{2}, 20.000,0 \mathrm{mg}$; Vit. $\mathrm{B}_{6}$, $12.000,0 \mathrm{mg}$; Vit. $\mathrm{B}_{12}, 60.000,0 \mathrm{mg}$; Biotina (Biotin), 320,0 mg; Ácido fólico (folic acid), 2.800 mg; Ácido nicotínico (nicotinic acid), $120.000,0$ mg; Ácido pantotênico (pantothenic acid), 40.000,0 mg; Se, $1.000,0 \mathrm{mg}$.

${ }^{4}$ Premix mineral (Mineral premix): $\mathrm{kg}$ do produto ( $\mathrm{kg}$ of product): $\mathrm{Mn}$, $150.000 \mathrm{mg} ; \mathrm{Zn}, 100.000 \mathrm{mg}$; Fe, $100.000 \mathrm{mg}$; Cu, $16.000 \mathrm{mg} \mathrm{e}$ I, $1.500 \mathrm{mg}$.

${ }^{5}$ Antioxidante. Composição BHA, BHT(Beta-hidroxi-tolueno), Galoto de propila, cabonato de cálcio (calcium carbonate). Níveis de garantia do produto (Levels least) - BHT $100 \mathrm{~g} / \mathrm{kg}$

${ }^{6}$ Análise realizada no Laboratório Mogiana Alimentos S/A.

${ }^{6}$ Analyzed at the Mogiana Alimentos S.A Lab.

maior valor do coeficiente de determinação $\left(R^{2}\right)$ e a significância a 5 ou $1 \%$ de probabilidade de acordo com o teste $\mathrm{F}$, uma vez respeitada a resposta biológica das aves. $\mathrm{Na}$ ausência de interações significativas $(\mathrm{P}>0,05)$, os níveis de lisina e de proteína foram estudados como efeitos principais.

\section{Resultados e Discussão}

Na Tabela 2 são apresentados os resultados de consumo de ração, produção, peso, massa, conversão por massa e por dúzia de ovos. À exceção da produção de ovos, as demais variáveis não apresentaram interação $(\mathrm{P}>0,05)$ dos níveis de lisina com os níveis de $\mathrm{PB}$ da ração e, portanto, somente os efeitos principais estão sendo apresentados.

$\mathrm{O}$ consumo de ração não sofreu efeito $(\mathrm{P}>0,05)$ dos níveis de lisina. Entretanto, a concentração de $\mathrm{PB}$ afetou, significativamente $(\mathrm{P}<0,05)$ o consumo, que diminuiu no nível de $20 \% \mathrm{~PB}$, em comparação ao observado no nível de 23\% PB (Tabela 2). Este resultado discordou daquele obtido por Murakami(1991) que, utilizando níveis de $16,18,20$ e $22 \%$ de PB, não observaram efeito significativo sobre o desempenho de codornas, nas fases de crescimento e postura.

Observou-se efeito $(\mathrm{P}<0,01)$ quadrático sobre a produção de ovos (Tabela 2; Figura 1), dos níveis de lisina dentro dos níveis de $20 \%$ PB $(\mathrm{P}<0,05)$ e $23 \%$ $\mathrm{PB}(\mathrm{P}<0,07)$ da ração, com pontos de máxima produção em $1,07 \%$ de lisina $(91,9 \% /$ ave/d) e $1,15 \%$ de lisina $(95,4 \% /$ ave/d), respectivamente. O nível de $23 \%$ de $\mathrm{PB}$ aumentou a produção de ovos em comparação com o nível de $20 \%$ de $\mathrm{PB}(\mathrm{P}<0,05)$ dentro dos níveis de $0,80,0,95,1,25$ e $1,40 \%$ de lisina.

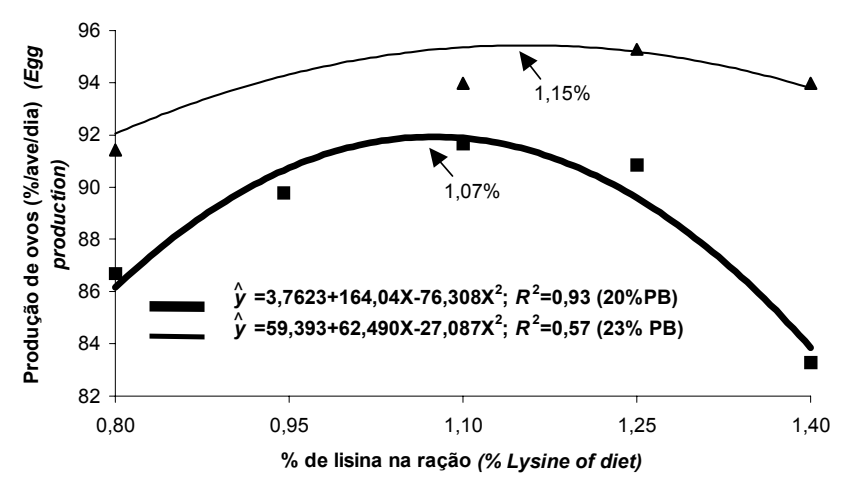

Figura 1 - Produção de ovos em função dos níveis de lisina $(X)$ e de cada nível de proteína bruta (PB) da ração de codornas.

Figure 1 - Egg production according to dietary lysine $(X)$ and each crude protein $(C P)$ levels of quail laying diet. 
Tabela 2 - Consumo de ração (CR), produção de ovos (PR), pesos dos ovos (PO), massa de ovos (MO), conversão por massa de ovos (CMO) e conversão por dúzia de ovos (CDO) de acordo com os níveis de proteína e lisina na ração

Table 2 - Feed intake (FI), egg production (EP), egg weight (EW), egg mass (EM), feed to egg dozen ratio(FDR) and egg feed to egg mass ratio (FMR), according to the dietary protein and lysine levels

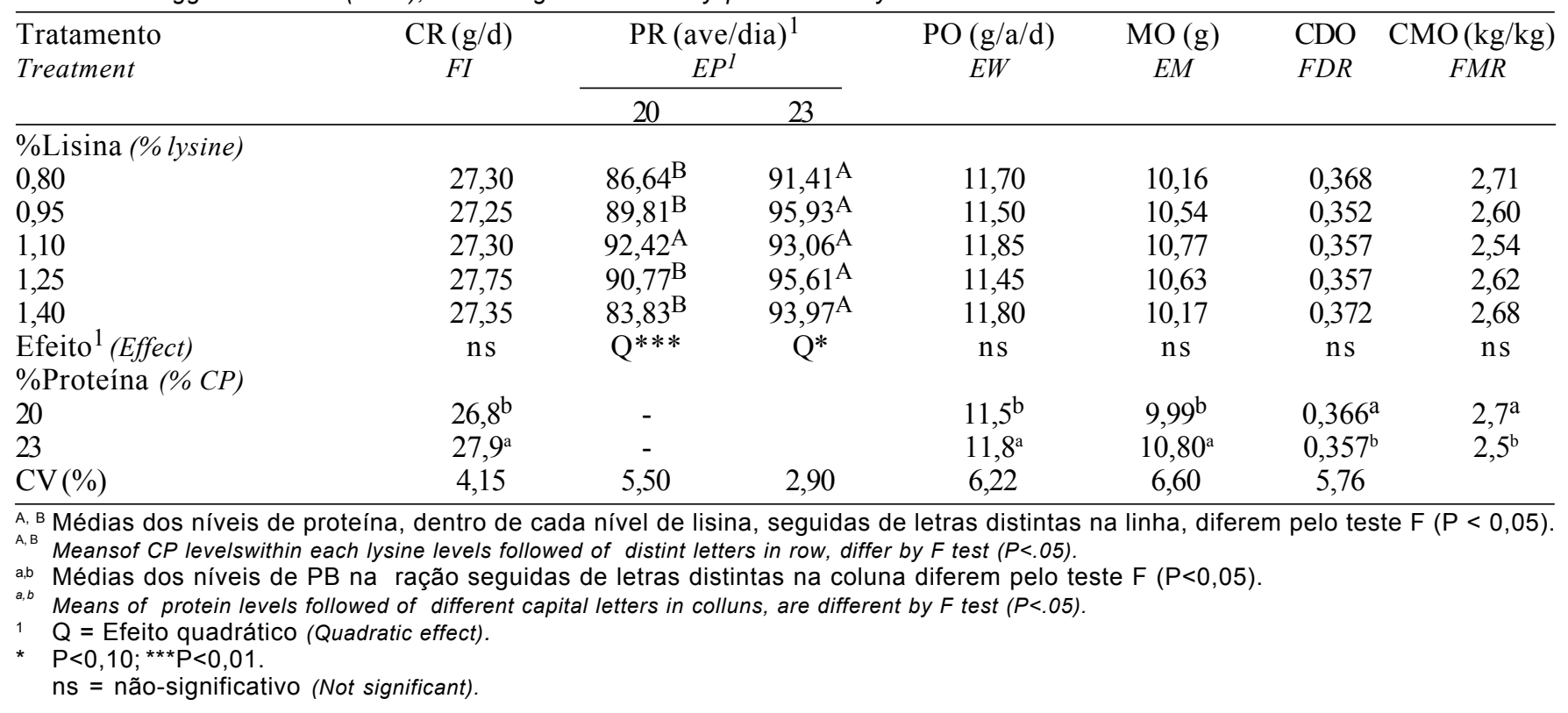

A estimativa da exigência de lisina obtida no presente trabalho com $20 \%$ de PB foi $7 \%$ maior que o nível de lisina recomendado pelo NRC (1994), com similar conteúdo de proteína bruta na ração. No entanto, a estimativa de exigência de lisina aumentou para $1,15 \%$, quando o nível de proteína da ração passou para $23 \%$, sendo $15 \%$ superior ao valor preconizado pelo NRC (1994) e $8 \%$ acima do valor estimado, quando a ração continha $20 \%$ de PB. Estes resultados, corroboram a hipótese de Morris et al. (1987) e Rose \& Uddin (1988) de que as exigências de lisina em frangos de corte crescem com o aumento do nível de proteína da ração. Silva et al. (1998a,b), também, observaram aumento percentual da exigência de metionina+cistina em frangos de corte quando a proteína da ração foi elevada. Estes resultados sugerem que semelhante ao ocorrido com outras espécies, a exigência quantitativa de lisina para codornas também aumenta com o nível de PB da ração.

Com base nas estimativas de exigências obtidas no presente trabalho, pode-se observar que a relação lisina: proteína não foi alterada, sendo de 5,3 e 5,0\%, respectivamente, com 20 e $23 \%$ de $\mathrm{PB}$ na ração, concordando com a proporção de lisina: $\mathrm{PB}$ de $5 \%$ recomendada pelo NRC (1994).

Allen \& Young (1980) recomendaram para uma ração com $18 \%$ de $\mathrm{PB}$ um percentual de $0,86 \%$ de lisina, resultando numa relação lisina: PB de 4,7\%, um pouco abaixo da obtida no presente estudo e àquela recomendada pelo NRC (1994).

Oliveira et al. (1999) trabalharam com duas relações lisina: proteína $(5,2$ e 7,01\%) e dois níveis de PB na ração $(19,0$ e 14,1\%). Os autores chegaram a conclusão que, a ração com baixa proteína $(14,1 \%)$, suplementada com lisina, não proporcionou a mesma resposta que a ração com nível ótimo de proteína (19\%). A explicação para a discrepância entre o resultado obtido por Oliveira et al. (1999) e o do presente estudo foi, provavelmente, decorrente do desequilíbrio protéico, aumentando o catabolismo e, conseqüentemente, desvio dos grupos aminos da lisina para a síntese de aminoácidos não-essenciais (glutamato) ou de ácido úrico, em virtude do baixo teor de PB da ração usada por aqueles autores.

$\mathrm{O}$ peso e as porcentagens de gema, albúmem e cascas (Tabela 3 ) não sofreram efeitos de interação $(\mathrm{P}>0,05)$ dos níveis de lisina com os níveis de $\mathrm{PB}$ das rações. Por outro lado, os pesos de gema e de albúmem foram afetados pelo nível de proteína da ração, crescendo à medida que o nível de proteína passou de 20 para $23 \%$. O valor percentual médio de gema de $31,19 \%$ obtido no presente experimento foi 
Tabela 3 - Peso da gema (PG), porcentagem de gema (\%G), peso do albúmen (PAL), porcentagem de albúmem (\%AL), peso da casca seca $(\mathrm{PC})$ e porcentagem de casca seca $(\% \mathrm{C})$ de acordo com os níveis de proteína e lisina da ração

Table 3 - Yolk weigh (YW), yolk percentage (YP), albumen weight (AW), albumen percentage (AP), egg shell weight (SW) and egg shell percentage (SP), in according to protein and lysine levels of diets

\begin{tabular}{|c|c|c|c|c|c|c|}
\hline $\begin{array}{l}\text { Tratamento } \\
\text { Treatment }\end{array}$ & $\begin{array}{c}\mathrm{PG}(\mathrm{g}) \\
Y W\end{array}$ & $\begin{array}{c}(\% \mathrm{G}) \\
Y P\end{array}$ & $\begin{array}{c}\operatorname{PAL}(\mathrm{g}) \\
\quad A W\end{array}$ & $\begin{array}{c}\% \mathrm{AL} \\
A P\end{array}$ & $\begin{array}{c}\mathrm{PC}(\mathrm{g}) \\
S W\end{array}$ & $\begin{array}{c}\% \mathrm{C} \\
S P\end{array}$ \\
\hline \multicolumn{7}{|c|}{$\%$ Lisina (\% lysine) } \\
\hline 0,80 & 3,62 & 30,93 & 7,12 & 60,87 & 0,96 & 8,19 \\
\hline 0,95 & 3,58 & 31,24 & 6,95 & 60,57 & 0,94 & 8,17 \\
\hline 1,10 & 3,70 & 31,30 & 7,14 & 60,46 & 0,97 & 8,25 \\
\hline 1,25 & 3,55 & 31,03 & 6,96 & 60,78 & 0,94 & 8,21 \\
\hline 1,40 & 3,71 & 31,41 & 7,76 & 60,62 & 0,95 & 7,97 \\
\hline Efeito (effect) & $\mathrm{ns}$ & $\mathrm{ns}$ & $\mathrm{ns}$ & $\mathrm{ns}$ & $\mathrm{ns}$ & $\mathrm{ns}$ \\
\hline \multicolumn{7}{|c|}{ \%Proteína (\% protein) } \\
\hline 20 & $3,58^{\mathrm{b}}$ & 31,09 & $7,00^{\mathrm{b}}$ & $60,76^{\mathrm{a}}$ & 0,94 & 8,14 \\
\hline 23 & $3,68^{\mathrm{a}}$ & 31,29 & $7,12^{\mathrm{a}}$ & $60,54^{\mathrm{b}}$ & 0,96 & 8,16 \\
\hline $\mathrm{CV}(\%)$ & 3,64 & 2,79 & 4,83 & 3,07 & 6,34 & 5,62 \\
\hline
\end{tabular}

A,B Médias dos níveis de proteína bruta, seguidas de letras distintas nas colunas, diferem pelo teste $F(P<0,05)$.

A, B Means of protein level of followed different capital letters in colluns, are different by $F$ test $(P<.05)$.

$\mathrm{ns}=$ não significativo (Not significant).

semelhante àquele citado por Murakami \& Ariki (1998) de 31,14\%. Da mesma forma, a porcentagem média de cascas de $8,15 \%$, assemelha-se àquela citada por Zampronio et al. (1996) de $8,11 \%$ e está pouco acima daquela de $7,62 \%$ observada por Masukawa et al. (1996).

\section{Conclusões}

As exigências de lisina total de codornas estimadas pela produção de ovos foram de $1,07 \%$ ou consumo de $287 \mathrm{mg} /$ dia com $20 \%$ de proteína na ração e de $1,15 \%$ ou consumo de $321 \mathrm{mg} / \mathrm{dia}$ com $23 \%$ de proteína na ração.

Codornas alimentadas com ração contendo $23 \%$ de proteína, apresentam melhor consumo de ração, peso dos ovos, massa de ovos, conversões por dúzia e por massa de ovos, pesos da gema e albúmen e porcentagem de albúmen que àquelas alimentadas com $20 \%$.

\section{Literatura Citada}

ALLEN, N.K.; YOUNG, R.J. Studies on the amino acid and protein requirements of laying japonese quail (Coturnix coturnix japonica). Poultry Science, v.59, p.20292037, 1980 .

FABICHAK, I. Codorna, criação, instalação e manejo. São Paulo: Nobel, 1987. 71p.

LEESON, S.; SUMMERS, J.D. Commercial poultry nutrition. 2.ed. Guelphy: University Books, 1997. 350p.

MATTOS FILHO, A.S.S.; PEDROSA, A.A.; MORAES, V.M.B. et al. Níveis de proteína em rações de codornas durante a fase de postura. Ars Veterinária, v.15, p.223-225, 1999.

MORRIS, T.R.; AL-AZZAWI, K.; GOUS, R.M. Effects of protein concentration on responses to dietary lysine by chicks. British Poultry Science, v.28, p.185-195, 1987.

MORRIS, T.R.; GOUS, R.M.; FISHER, C. An analysis of the hypothesis that amino acid requirements for chicks should be stated as a proportion of dietary protein. World's Poultry Science Journal, v.55, p.7-22, 1999.

MURAKAMI, A.E. Níveis de proteína e energia em ração para codornas japonesas (Coturnix coturnix japonica) nas fases de crescimento e postura. Jaboticabal: UNESP, 1991. 98p. Tese (Doutorado em Zootecnia) - Universidade Estadual Paulista, 1991.

MURAKAMI, A.E.; ARIKI, J. Produção de codorna japonesa. Jaboticaba: Funep, 1998. 79p.

MURAMATSU, T.; HIRAMOTO, K.; TAKASI, I. et al. Effect of protein starvation on protein turnover in liver, oviduct and whole body of laying hens. Comparative Biochemistry and Physiology, v.87, p.227-232, 1987.

NATIONAL RESEARCH COUNCIL - NRC. Nutrient requirements of poultry. 9.ed., 1994. 155p.

OLIVEIRA, A.M.; FURLAN, A.C.; MURAKAMI., A.E. et al. Exigência nutricional de lisina para codornas japonesas (Coturnix coturnix japonica) em postura. Revista Brasileira de Zootecnia, v.28, p.1050-1053, 1999.

PINTO, R.; FERREIRA, A.S.; ALBINO, L.F.T. et al. Níveis de proteína para codornas japonesa em postura. In: REUNIÃO ANUAL DA SOCIEDADE BRASILEIRA DE ZOOTECNIA, 35., 1998, Botucatu. Anais... Botucatu: Sociedade Brasileira de Zootecnia,1998. p.147-147.

ROSE, S.P.; UDDIN, M.S. Effect of temperature on the response of broiler chickens to dietary lysine balance. British Poultry Science, v.39, p.36-37, 1988.

ROSTAGNO, H.S.; ALBINO, L.F.T.; DONZELE, J.L. et al. Tabelas brasileiras para aves e suínos (Composição de alimentos e exigências nutricionais). Viçosa, MG: 
Universidade Federal de Viçosa, 2000. 141p.

SHIM, K.F.; VOHRA, P. A review of the nutrition of Japonese quail. World's Poultry Science Journal, v.40, p.261274, 1984.

SILVA, J.H.V.; RIBEIRO, L.G.R. Tabela nacional de exigência nutricional de codornas japonesas (Coturnix coturnix japonica). Bananeiras, PB: DAP/UFPB/Campus IV, 2001. 19p.

SILVA, M.A.; ALBINO, L.F.T.; ROSTAGNO, H.S. et al. Níveis de metionina+cistina e de proteína bruta para frangos de corte. Revista Brasileira de Zootecnia, v.27, p.350-356, 1998a.

SILVA, M.A.; ALBINO, L.F.T.; ROSTAGNO, H.S. et al. Exigências nutricionais de metionina+cistina para pintos de corte, em função do nível de proteína bruta da ração. Revista Brasileira de Zootecnia, v.27, p.357-363, 1998 b.
UNIVERSIDADE FEDERAL DE VIÇOSA - UFV. SAEG (Sistema de Análises Estatísticas e Genéticas). Versão 4.0. Viçosa, MG, 1983. 69p. (Manual do usuário).

ZAMPRONIO, E.C.; MORAES, V.M.B.; MALHEIROS, R.D. Efeito da muda forçada sobre o desempenho produtivo e qualidade do ovo em codornas (Coturnis coturnix japonica). In: REUNIÃO ANUAL DA APINCO'96, Campinas. Anais... Campinas: FACTA, 1996. p.12.

Recebido em: 05/11/01

Aceito em: 19/09/02 